Research Article

\title{
Electric Resistance Tests on Compacted Clay Material under Dynamic Load Coupled with Dry-Wet Cycling
}

\author{
Zheng Lu $\left(\mathbb{D},{ }^{1}\right.$ Xiaowen Wu, ${ }^{1,2}$ Zhi Hu, ${ }^{2}$ Shaohua Xian, ${ }^{1}$ and Ran Fang ${ }^{1}$ \\ ${ }^{1}$ State Key Laboratory of Geomechanics and Geotechnical Engineering, Institute of Rock and Soil Mechanics, \\ Chinese Academy of Sciences, Wuhan 430071, China \\ ${ }^{2}$ School of Civil Engineering, Architecture and Environment, Hubei University of Technology, Wuhan 430068, China
}

Correspondence should be addressed to Zheng Lu; lzwhrsm@163.com

Received 20 November 2017; Accepted 1 April 2018; Published 15 April 2018

Academic Editor: João M. P. Q. Delgado

Copyright (c) 2018 Zheng Lu et al. This is an open access article distributed under the Creative Commons Attribution License, which permits unrestricted use, distribution, and reproduction in any medium, provided the original work is properly cited.

\begin{abstract}
The study of compacted clay material under dynamic load coupled with dry-wet cycling is one of the most important areas in the field of transportation. In this paper, experiments in terms of compacted clay under dynamic load coupled with dry-wet cycling are performed, and synchronous resistivity tests are also conducted. According to the test results, the influences of cumulative plastic strain, dry-wet cycles, and amplitudes on the soil resistivity are analyzed. Then a new damage factor based on resistivity is proposed to evaluate the long-term performance of compacted clay material. The result of research shows that the evolution of the soil resistivity can be divided into two stages, which has a contrary tendency with that of cumulative plastic strain. The dry-wet cycles and amplitudes have a significant effect on the damage of the compacted soil, which indicates that the dry-wet cycling of compacted soil materials should not be ignored in road engineering, especially in rainy and humid areas.
\end{abstract}

\section{Introduction}

Roadways and railways commonly consist of upper pavement or ballast layers (track slab) over one or more silty clay layers which are together compacted over a suitable soil subgrade. As it is well known, compacted clay material provides the most important structural element in the road system because, in most cases, the cumulative deformation phenomenon takes place mainly in the subgrade layer causing progressive fatigue cracking of upper road layers [1-3]. So, it is essential to control the long-term performance of the subgrade so as to carry traffic safely, conveniently, and economically during its entire lifespan. However, the subgrade suffers from the humidity change and variation of temperature for a long term; besides, the cyclic traffic loads and other climate also bring adverse effects on it. Therefore, it is of great significance to study the long-term performance and damage laws of compacted clay material under the comprehensive effect of dynamic load and dry-wet cycling.

The damage of compacted soil is usually accompanied by the change of soil structure, and the electric resistance can reflect the feature of the composition of soil particles and pore structure well. Thus, resistivity can be used in the study of soil structure change and structural damage [4]. Archie [5] first studied the relationship between soil resistivity and its structure and proposed the soil structural factorresistivity structure factor $\mathrm{F}$ (formation resistivity factor). Then, he established the exponential function relation between resistivity structure factor and sandy soil porosity. Miao et al. [6,7] investigated the resistivity characteristic of cement-stabilized soil; the relationship between soil resistivity and unconfined compressive strength, cement mixing ratio, and age were obtained. Fukue and Liu et al. [8-10] developed a geotechnical resistivity test system and established the resistivity model of expansive soil and soft soil structure, and they put forward an average apparent structure factor concept for this type of soil. Subsequently, Lin et al. [11] conducted indoor experiments on the resistivity of loess, on the basis of which the influence of contact pressure, temperature, and measurement frequency on resistivity was studied and the variation rule of the resistivity of loess was analyzed. However, the literature on 
TABLE 1: Material properties of the compacted clay.

\begin{tabular}{lcccccccc}
\hline $\begin{array}{l}\text { Natural water } \\
\text { content }(\%)\end{array}$ & $\begin{array}{c}\text { Natural } \\
\text { density } \\
\left(\mathrm{g} / \mathrm{cm}^{3}\right)\end{array}$ & $\begin{array}{c}\text { Saturated water } \\
\text { content }(\%)\end{array}$ & $\begin{array}{c}\text { Plastic } \\
\text { limit }(\%)\end{array}$ & $\begin{array}{c}\text { Liquid } \\
\text { limit }(\%)\end{array}$ & $\begin{array}{c}\text { Specific } \\
\text { gravity }\end{array}$ & $\begin{array}{c}\text { Maximum dry } \\
\text { density }\left(\mathrm{g} / \mathrm{cm}^{3}\right)\end{array}$ & $\begin{array}{c}\text { Optimum water } \\
\text { content }(\%)\end{array}$ & $\begin{array}{c}\text { Permeability } \\
(\mathrm{cm} / \mathrm{s})\end{array}$ \\
\hline 23.7 & 1.68 & 23.8 & 21.1 & 34.8 & 2.72 & 1.90 & 14.1 & $6.5 \mathrm{e}-7$ \\
\hline
\end{tabular}

TABLE 2: Testing program of dynamic load coupled with dry-wet cycling.

\begin{tabular}{lc}
\hline Parameters & Values \\
\hline Initial water content $(\%)$ & 14.1 \\
Number of drying-wetting cycles & $0,2,4,9$ \\
Amplitude of drying-wetting cycles $( \pm \%)$ & $0,2,4,6$ \\
Initial static deviatoric stress $(\mathrm{kPa})$ & 20 \\
Confining pressure $(\mathrm{kPa})$ & 40 \\
Amplitude of dynamic stress $(\mathrm{kPa})$ & 40 \\
Loading frequency $(\mathrm{Hz})$ & 5 \\
Number of loading cycles & $10^{5}$ \\
\hline
\end{tabular}

electric resistance tests on compacted clay material under dynamic load coupled with dry-wet cycling is rarely published. Therefore, experiments of dynamic load coupled with dry-wet cycling are performed in this paper, and the synchronous resistivity tests on compacted clay material are conducted at the same time. According to the experimental results, the evolution of resistivity with cumulative plastic strain, dry-wet cycles, and amplitudes is analyzed, and then, a damage factor based on resistivity is proposed to evaluate the long-term performance of compacted clay material. The study can provide a reference for the damage assessment of the compacted subgrade soil under complex environment and traffic loads.

\section{Experimental Procedures}

The experimental clay material was taken from Sanmenxia along the Zhengxi Passenger Railway in China. The main material characteristics are listed in Table 1. All the test samples are reshaped in a cylinder-shaped sampler of $76 \mathrm{~mm}$ in height and $38 \mathrm{~mm}$ in diameter. The samples are compacted to an initial dry density of $1.81 \mathrm{~g} / \mathrm{cm}^{3}$ to meet the compaction requirement's degree of the specification [12].

In order to simulate the actual service condition of the road subgrade under traffic loads and climate changes, dynamic triaxial tests are conducted on the samples subjected to different dry-wet cycles and amplitudes. Aimed at simulating the field stress state of subgrade soil, the bias consolidation of the soil samples is carried out under a certain confining pressure for 15 hours before starting the triaxial tests. The experimental scheme for the dynamic load coupled with dry-wet cycling is designed and shown in Table 2. In fact, the testing program shown in Table 2 is designed according to the practical road subgrades subjected to traffic loads and climate changes. It is reported that the mechanical properties of compacted clay soil could finally tend to stabilize after $8 \sim 10$ dry-wet cycles. Thus, the maximum number of drying-wetting cycles is fixed at 9 in this research. Moreover, in terms of clay soil material, the maximum water content of subgrades under climate changes is usually no more than $\mathrm{OWC}+6 \%$ (here, OWC means the optimum water content of subgrades). The maximum amplitude of drying-wetting cycles is fixed at $6 \%$ in the experiment.

For the purpose of describing the damage state of compacted clay material under dynamic load coupled with dry-wet cycling, the soil sample resistivity is tested simultaneously with the dynamic triaxial test in this paper. According to the principle of measurement, the resistivity test method can be divided into the dipole method and the quadrupole method [13], and the two kind of measuring devices are shown in Figure 1. The quadrupole method provides a certain voltage through a type $A B$ electrode, the resistance of soil sample can be obtained by the means of measuring the voltage of MN electrode and the current in the pathway, and then the soil sample resistivity will be obtained through the resistivity calculation formula. The dipole method is a special case that the electrode $\mathrm{MN}$ is shared with the electrode $A B$ in the quadrupole method. When using the dipole method, the contact resistance will be greater because of the poor contact with the electrode and the soil sample; therefore, contact resistance size should be determined before the formal test [14]. The quadrupole method has the advantages of not considering the contact resistance compared to the dipole method, but the measuring electrode usually needs to be inserted into the soil sample. Thus, it is not suitable for the measurement of resistivity for which soil sample integrity requirements are high. For this purpose, the dynamic triaxial apparatus is upgraded and modified to satisfy the synchronous test requirements of dynamic characteristics and resistivity of the samples, as shown in Figure 2. In terms of the soil sample integrity, circuit installation, and operability of instrument, the dipole method is adopted to measure the soil sample resistivity in this paper. The resistivity is collected by WDJD4 multifunctional digital DC exciter, as shown in Figure 3.

It is noted that temperature can affect the soil resistivity significantly; thus, the measured resistivity needs to be corrected. In this paper, the resistivity tests are firstly carried out at different temperatures to derive the temperature correction curve, as shown in Figure 4. In order to eliminate the effect of temperature, the resistivity of the soil sample in the standard state is adopted uniformly in the following analysis. According to the test results, the relationship between the resistivity of the standard state and the measured resistivity can be described by using the following formula:

$$
\rho_{25}=\rho_{\mathrm{T}}[1+\alpha(T-25)]
$$

where $\rho_{25}$ and $\rho_{\mathrm{T}}$ are the soil sample resistivity of the standard state $\left(25^{\circ} \mathrm{C}\right)$ and the measured temperature, $\mathrm{T}\left({ }^{\circ} \mathrm{C}\right)$, respectively. $T$ is the experimental temperature, $\alpha$ is the 


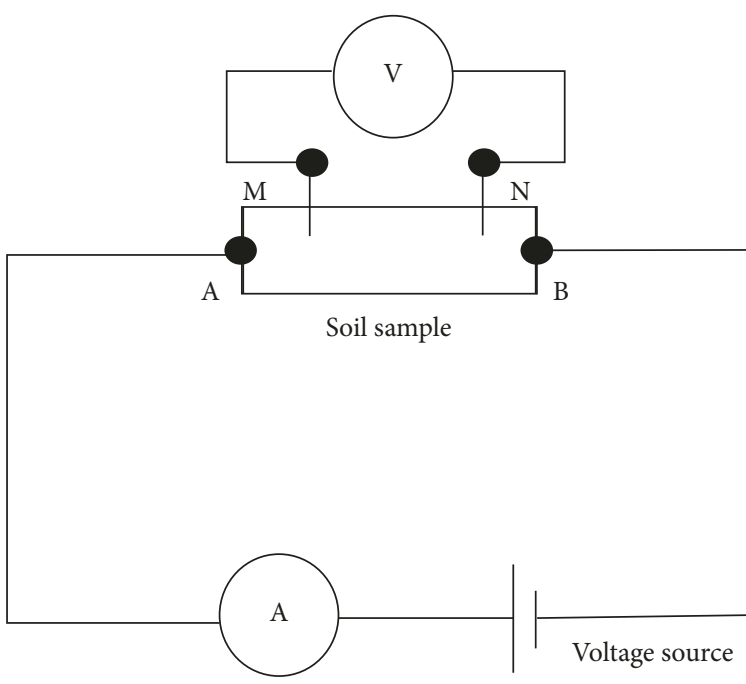

(a)

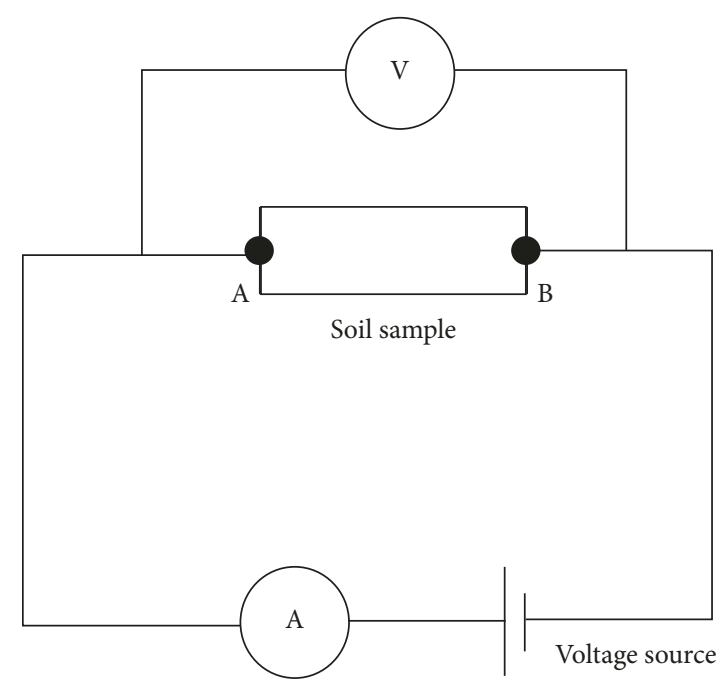

(b)

Figure 1: Resistivity test method for the soil samples: (a) the quadrupole method and (b) the dipole method.

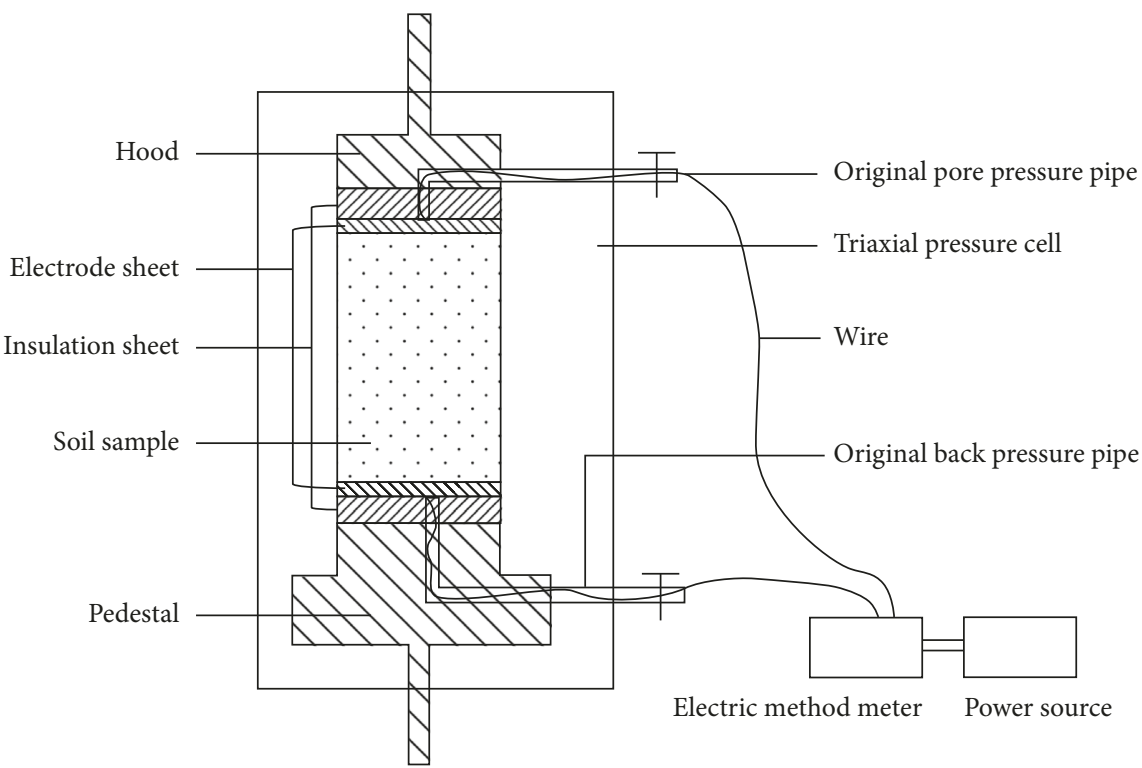

FIGURE 2: Schematic diagram of the soil sample resistivity test on the dynamic triaxial apparatus.

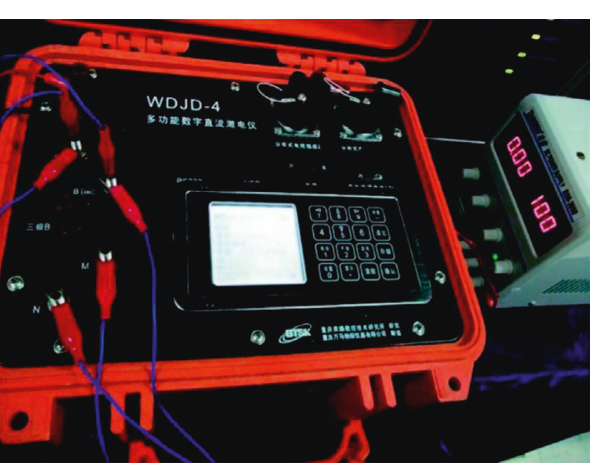

FIGURE 3: Soil resistivity acquisition instrument.

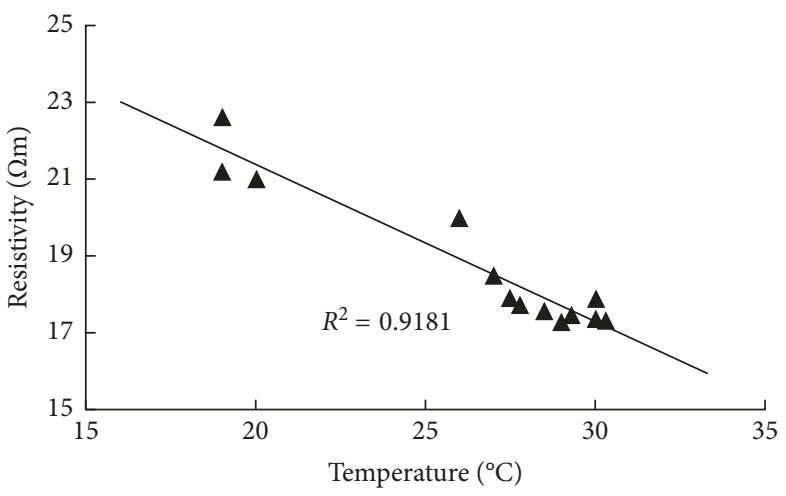

FIGURE 4: Temperature correction curve for soil sample resistivity. 


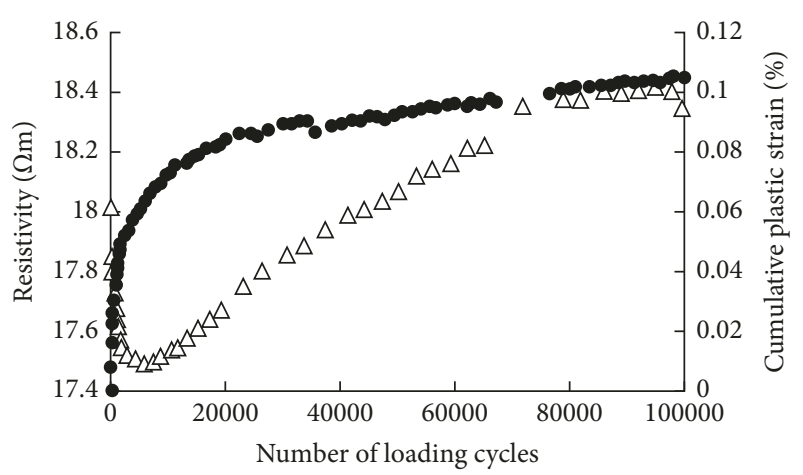

$\Delta$ Resistivity

- Cumulative plastic strain

Figure 5: Variations of the soil sample resistivity and cumulative plastic strain with the number of loading cycles.

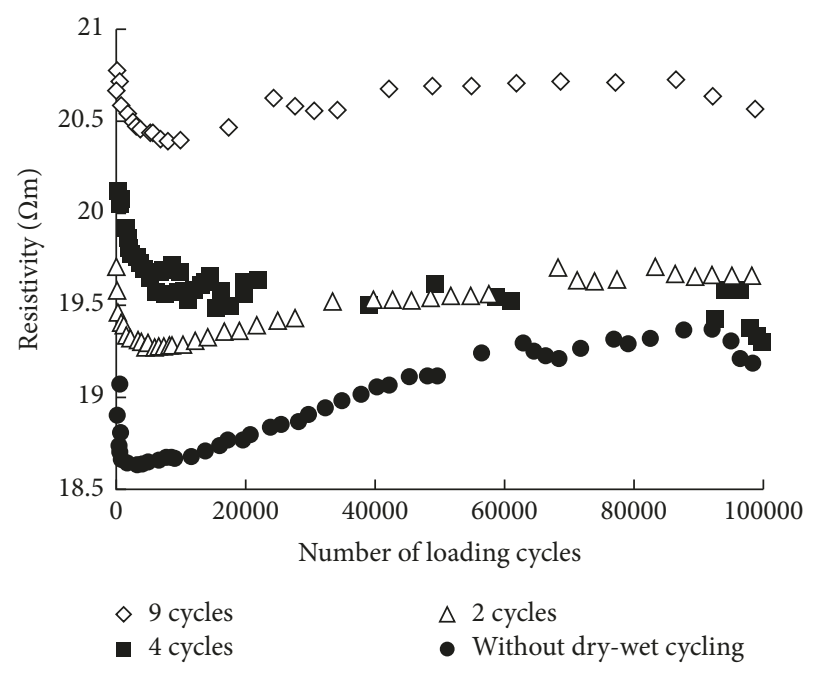

FIgURE 6: Effect of dry-wet cycles on the soil sample resistivity.

temperature correction coefficient, and $\alpha=0.0207^{\circ} \mathrm{C}^{-1}$ in this paper based on the test results.

The measured resistivity is calculated by the following equation:

$$
\rho_{\mathrm{T}}=\frac{\left(\Delta U-\Delta U_{\mathrm{sp}}\right) S}{I L},
$$

where $\Delta U$ is the voltage between the two electrodes, $\Delta U_{\mathrm{sp}}$ is the initial potential difference, $I$ is the current value of the soil sample, and $S$ and $L$ are the surface area and height of the soil sample, respectively.

\section{Results and Discussion}

Figure 5 shows the variations of the soil sample resistivity and cumulative plastic strain with the number of loading cycles. It can be seen from Figure 5 that the evolution of the resistivity can be divided into two stages. The first stage is the early stage of cyclic loading: the cumulative plastic strain of soil sample increases rapidly and the resistivity decreases greatly. With the growth of the accumulative plastic strain,

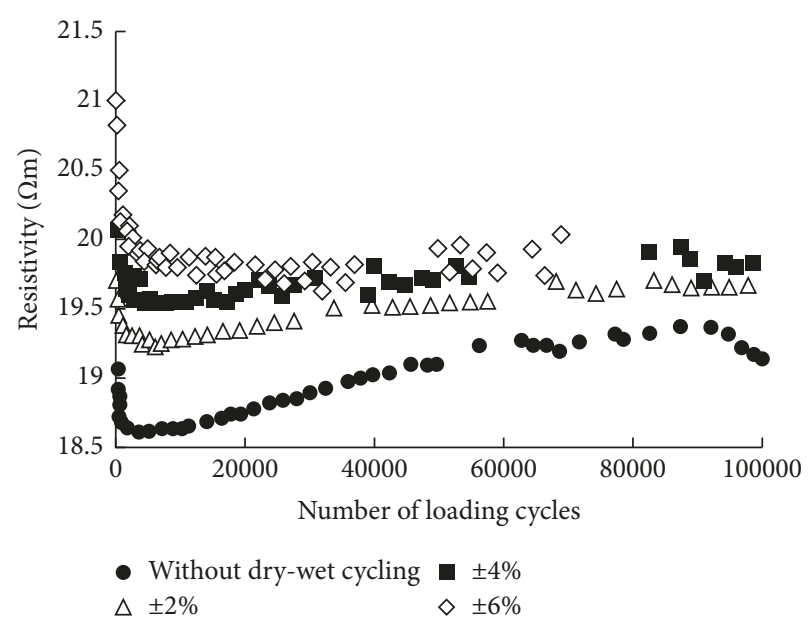

FIgURE 7: Effect of dry-wet cycling amplitudes on the soil sample resistivity.

the soil sample resistivity further reduces and then reaches the minimum value at a certain number of loading cycles. The second stage is the late cyclic loading: the growth rate of the accumulative plastic strain continues to decrease, and the values of accumulative plastic strain gradually stabilize. However, the soil sample resistivity increases inversely with the increasing loading cycles. At the first stage, the native micropores and microfractures of the soil sample gradually close because of the initial loadings, which causes larger soil compactness and better interconnectedness of pore water, thus leading to the increase of conductive passage in the soil sample [6]. When the resistivity reaches the minimum, the repair of the internal defect of the soil sample reaches its limit. At the second stage, the resistivity of the soil sample increases inversely, which indicates that the cyclic load causes new micropores or microcracks. The above results show that the resistivity can reflect the damage state and the process of damage evolution of the soil sample.

Figure 6 presents the variations of the soil sample resistivity with the number of loading cycles for different drywet cycles. It can be seen that the soil sample resistivity decreases initially, increases with the increasing number of loading cycles, and finally tends to stabilize, which are consistent with the rule of Figure 5. It also can be observed from Figure 6 that the soil sample resistivity increases gradually with the increasing dry-wet cycles, which indicates that the repeated dry-wet cycling can cause internal damage of the soil sample, thus leading to the density decrease. The effects of the dry-wet cycling amplitude on the soil sample resistivity are investigated in Figure 7 . It can be seen from Figure 7 that the soil sample resistivity increases with the increase of the dry-wet cycling amplitude. This indicates that the different dry-wet cycling amplitudes can also cause internal damage and reduce compactness of the clay soil and thus results in a strength decreasing, which is consistent with those results obtained by Liu et al. $[15,16]$. Therefore, the resistivity can be used to determine the strength of compacted soil materials indirectly, and then the internal damage of the subgrade under complex environment and 


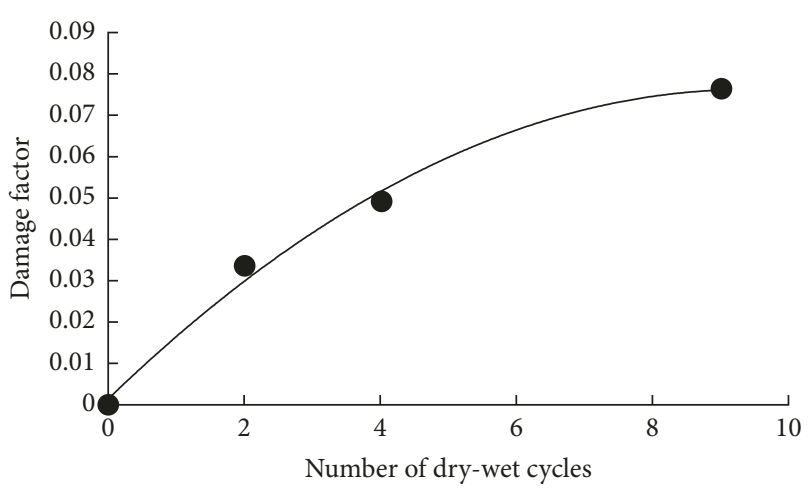

Figure 8: Variation of damage factor with the dry-wet cycles.

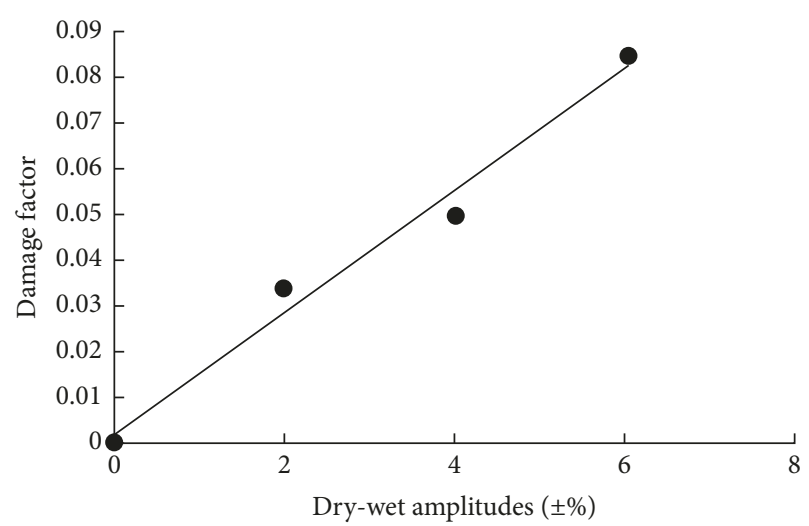

Figure 9: Variation of damage factor with the dry-wet amplitudes.

load can also be evaluated by adopting the resistivity measuring method.

In order to evaluate the damage property of compacted clay soil materials quantitatively using the resistivity measuring method, a damage factor based on resistivity is defined by the following equation:

$$
D_{\rho}=1-\frac{\rho_{0}}{\rho},
$$

where $D_{\rho}$ is the soil damage factor based on resistivity. Here, $D_{\rho}$ is defined as a parameter to indicate the soil degradation. The bigger the parameter, the more serious the damage is. $\rho_{0}$ is the resistivity of the nondestructive soil sample. Here, the samples not experiencing the dynamic load coupled with dry-wet cycling are considered as nondestructive soil. $\rho$ is the resistivity of the damage soil.

According to the above definition, the resistivity of the nondestructive soil sample can be measured, $\rho_{0}=19.07 \Omega \mathrm{m}$ in this paper. By employing (3), the damage characteristics of compacted soil materials under the dynamic load coupled with dry-wet cycling can be evaluated and analyzed. The measured sample resistivity increases with the increasing number and amplitude of drying-wetting cycles, but no more than $20.95 \Omega \mathrm{m}$ in this paper. Therefore, the values of the damage factor defined in (3) vary from 0 to 0.1 , as far as Sanmenxia clay material is concerned. The variations in the damage factor of compacted soil with the dry-wet cycles and amplitudes are presented in Figures 8 and 9, respectively. As can be seen from Figure 8 that when there is a small number of dry-wet cycles, the damage factor increases dramatically with increasing dry-wet cycles. However, when the number of dry-wet cycles exceeds 4 , the effect of the dry-wet cycles on the damage factor becomes relatively slight. This indicates that the long-term performance of compacted soil will tend to be stable after a certain number of dry-wet cycles. It can be observed from Figure 9 that the damage factor increases almost linearly with the increase of the dry-wet amplitudes. This result reveals that the dry-wet amplitudes have a significant effect on the damage of the compacted soil. The dry-wet cycling of compacted soil materials should not be ignored in road engineering, especially in rainy and humid areas.

\section{Conclusions}

In this paper, a series of experiments of dynamic load coupled with dry-wet cycling are performed, and the synchronous resistivity tests on compacted clay material are conducted. The influences of cumulative plastic strain, drywet cycles, and amplitudes on the soil resistivity are analyzed. Furthermore, a new damage factor based on resistivity is proposed to evaluate the long-term performance of compacted clay material. The main conclusions of this study can be summarized as follows:

(1) The evolution of the soil resistivity can be divided into two stages. The first stage is the early stage of cyclic loading: the cumulative plastic strain of soil sample increases rapidly and the resistivity decreases greatly. The second stage is the late cyclic loading: the soil sample resistivity increases inversely with the increasing loading cycles. It shows that the resistivity can reflect the damage state and the process of damage evolution of compacted clay material.

(2) The repeated dry-wet cycling can cause internal damage of the soil sample, thus leading to the density decrease. Therefore, the resistivity can be used to determine the strength of compacted soil materials indirectly, and then the internal damage of the subgrade under complex environment and load can also be evaluated by adopting the resistivity measuring method.

(3) The dry-wet cycles and amplitudes have a significant effect on the damage of the compacted soil, which indicates that the dry-wet cycling of compacted soil materials should not be ignored in road engineering, especially in rainy and humid areas.

\section{Conflicts of Interest}

The authors declare that they have no conflicts of interest.

\section{Acknowledgments}

This work was supported by the Youth Innovation Promotion Association, CAS, the outstanding youth fund of Hubei Province (2017CFA056), the Technology Service 
Network Initiative (no. KFJ-STS-ZDTP-037), and the National Natural Science Foundation of China (nos. 41472286, 41472290, and 41672312).

\section{References}

[1] N. D. Beskou and D. D. Theodorakopoulos, "Dynamic effects of moving loads on road pavements: a review," Soil Dynamics and Earthquake Engineering, vol. 31, no. 4, pp. 547-567, 2011.

[2] A. Gomes Correia and J. Cunha, "Analysis of nonlinear soil modelling in the subgrade and rail track responses under HST," Transportation Geotechnics, vol. 1, no. 4, pp. 147-156, 2014.

[3] Z. Lu, H. Yao, J. Liu, and Z. Hu, "Experimental evaluation and theoretical analysis of multi-layered road cumulative deformation under dynamic loads," Road Materials and Pavements Design, vol. 15, no. 1, pp. 35-54, 2014.

[4] H. E. Stewart, "Permanent strains from cyclic variableamplitude loadings," Journal of Geotechnical Engineering, vol. 112 , no. 6, pp. 646-660, 1986.

[5] G. E. Archie, "The electrical resistivity log as an aid in determining some reservoir characteristics," Transactions of the AIME, vol. 146, no. 1, pp. 54-62, 1942.

[6] L. Miao, S. Liu, M. Yan et al., "Research on resistivity characteristics of water soil," Engineering Survey, vol. 5, pp. 32-34, 2000.

[7] S. Jie, L. Shucai, L. Bin, X. Xinji, W. Chuanwu, and N. Lichao, "Quantitative evaluation method of unsaturated soil compaction based on resistivity characteristics," Journal of Chang'an University: Natural Science Edition, vol. 35, no. 6, pp. 33-41, 2015.

[8] M. Fukue, T. Minato, H. Horibe, and N. Taya, "The microstructures of clay given by resistivity measurements," Engineering Geology, vol. 54, no. 1-2, pp. 43-53, 1999.

[9] S. Liu, S. Zhan, and X. J. Yu, "Research on the resistivity of soil test," Journal of Engineering Geology, vol. 14, no. 2, pp. 216-222, 2006.

[10] S. Chunni, F. Xiang, W. Hewen, S. Shuguo, and G. Jianfeng, "The influence of suction, moisture content and dry density on the shear strength of unsaturated soil," Rock and Soil Mechanics, vol. 30, no. 5, pp. 1347-1351, 2009.

[11] W. Lin hao, B. Xiaohong, and F. Junqin, "Discussion on the influencing factors of the shear strength index of compacted loess soil," Journal of Geotechnical Engineering, vol. 32, no. S2, pp. 132-135, 2010.

[12] Ministry of Communications of the China, JTG D30-2015, Specifications for Design of Highway Subgrades, China Communication Press, Beijing, China, 2015.

[13] L. Miao, S. Liu, M. Yan et al., "Resistivity characteristics of water clay and its engineering application," Journal of Rock Mechanics and Engineering, vol. 20, no. 1, pp. 126-130, 2001.

[14] X. Yu, Research on the Application of Soil Mechanics of Resistivity Structure Model, Southeast University, Nanjing, China, 2004.

[15] S. Liu, L. Han, and Y. Du, "The resistivity characteristics and application of water soil," Journal of Geotechnical Engineering, vol. 28, no. 11, pp. 1921-1926, 2006.

[16] Z. Liu, Y. Zhang, W. Fang et al., "Research on the relationship between the resistivity of loess and its compaction characteristics," Journal of Xi'an University of Science and Technology, vol. 33, no. 1, pp. 84-90, 2013. 


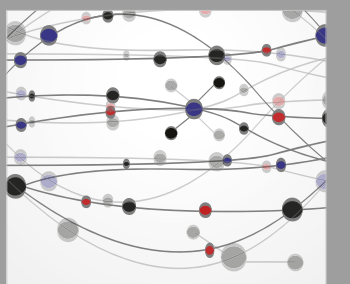

The Scientific World Journal
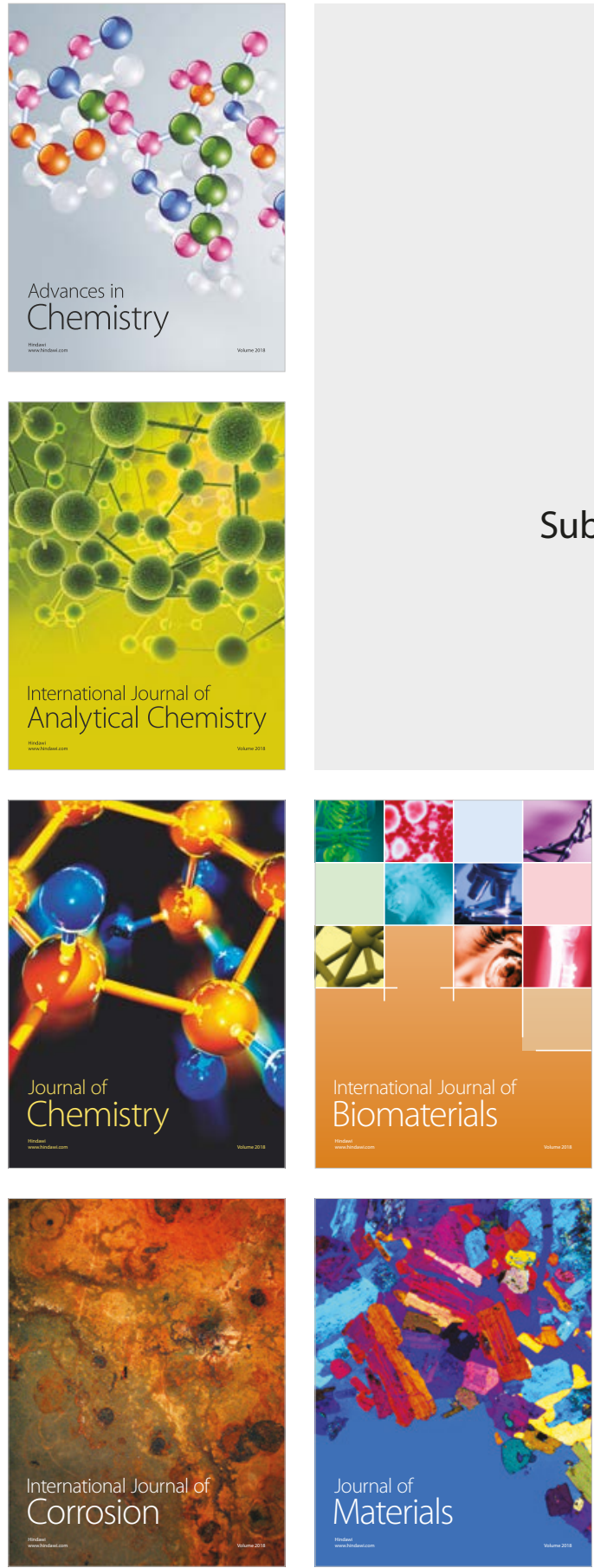

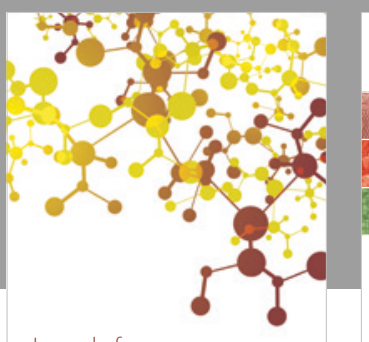

Journal of

Applied Chemistry
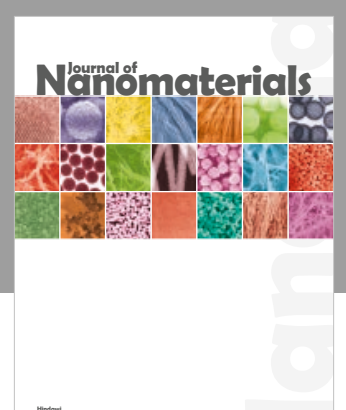

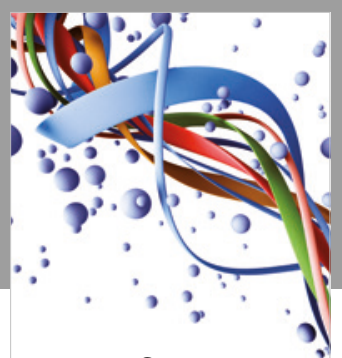

Scientifica

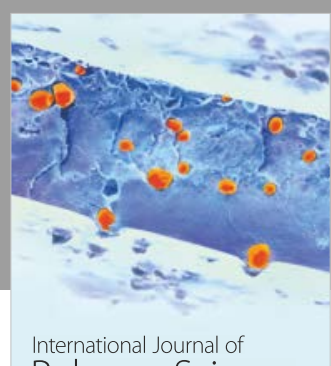

Polymer Science

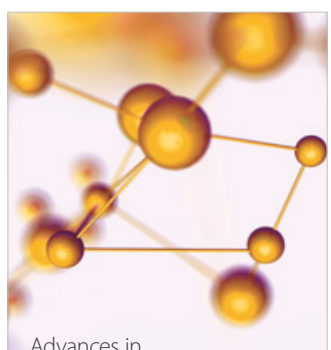

Physical Chemistry
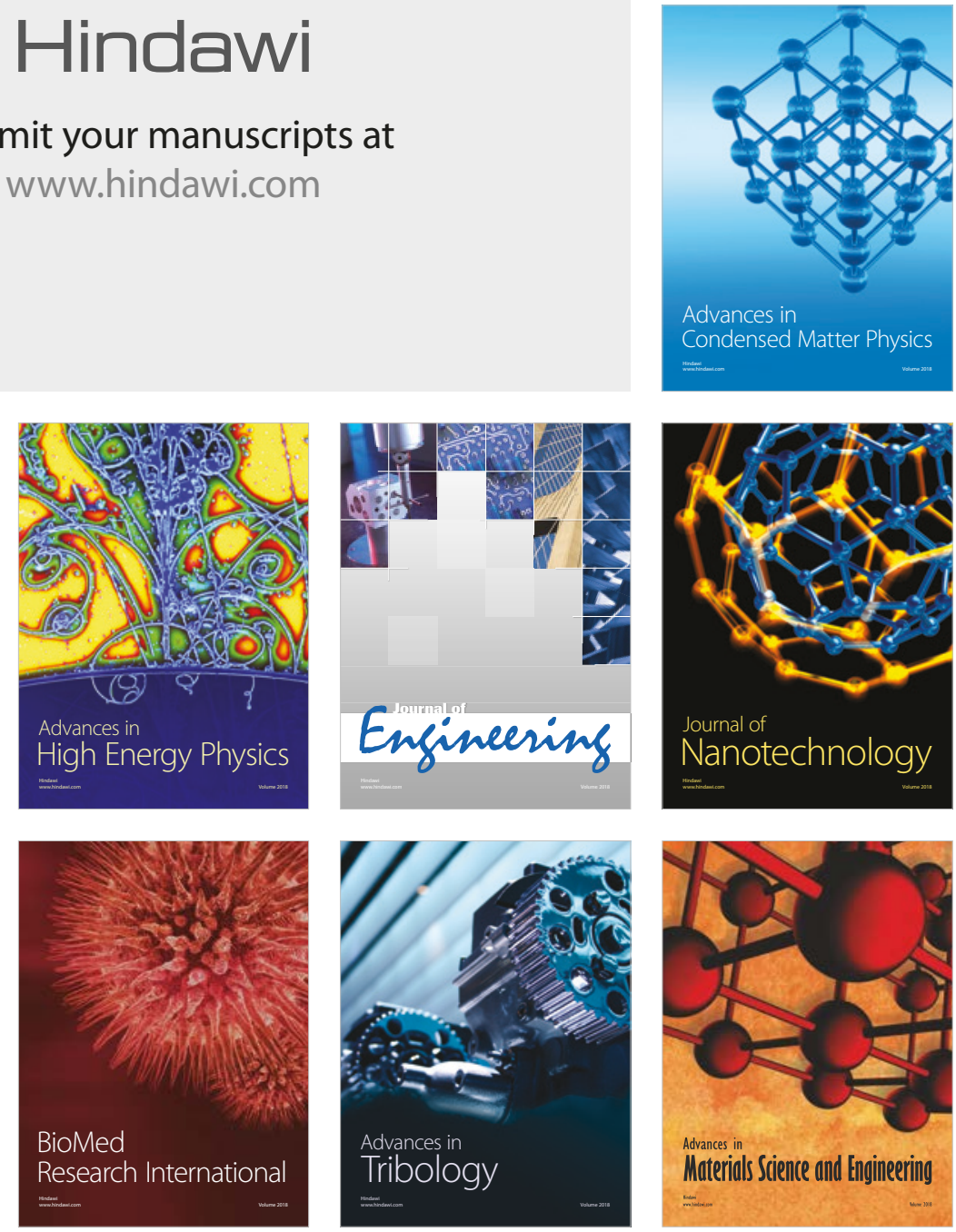